\title{
CINEMA E EDUCAÇÃO: DA REPRODUTIBILIDADE TÉCNICA À AÇÃO CINECLUBISTA EMANCIPADORA
}

\author{
Alessandro Reina ${ }^{1}$
}

RESUMO: O presente artigo tem como objetivo discorrer sobre o uso do filme como possibilidade de educação do pensamento por intermédio da prática cineclubista. Investiga primeiramente o cinema como elemento da indústria cultural através da sua contraposição com o cinemaarte. Posteriormente, investiga a possibilidade do uso da prática cineclubista como instrumento de esclarecimento e emancipação dos alunos no interior da escola dentro de uma proposta pedagógica para sua utilização.

PALAVRAS-CHAVE: Cinema; Escola; Educação; Cineclube.

ABSTRACT: This article aims to discuss the use of film as a possibility for education of thought through the film club practice. First investigates the film as part of the cultural industry through its opposition to the cinema art. Later investigates the possibility of using film club practice as enlightenment tool and emancipation of the students inside the school within a pedagogical proposal for its use.

KEYWORDS: Cinema; School; Education; Film Club. 


\section{PARTE1 - A REPRODUTIBILIDADE E O PROBLEMA DO CINEMA COMO ARTE}

Pensar sobre a utilização do cinema como um elemento decisivo para a educação não é algo recente. Serrano, em 1931, já pensava a utilização do cinema na sala de aula como um fator educativo. O cenário da época reportava à influência das ideias pedagógicas difundidas por Dewey nos Estados Unidos, onde o movimento escolanovista estava em destaque.

Porém o cinema sempre foi visto com uma certa desconfiança quando tratado como um instrumento educativo. O cinema, desde sua primeira exibição pública em 1985 na França, sempre se mostrou como um elemento da indústria cultural, sendo inicialmente tomado como um fenômeno da cultura de massa, ao mostrar imagens que remetiam ao cotidiano de pessoas, e posteriormente tomado como um grande empreendimento com a fundação dos grandes estúdios cinematográficos como a MGM (Metro Goldwyn Mayer) fundada em 1924 e a Paramount Pictures em 1912, ambas nos Estados Unidos. A verdade é que o cinema em sua origem não era tomado com arte, apenas como entretenimento. O cinema era apenas mais uma atração que tinha como objetivo fomentar o lucro, inicialmente sem nenhuma intencionalidade ou comprometimento com a formação cultural humana.

Esta condição de enfado dada ao cinema só muda em 1912, quando Ricciotto Canudo escreve um manifesto, intitulado Manifesto das Sete Artes e Estética da Sétima Arte, (publicado somente em 1923) em que propõe que a 
lista das artes, anteriormente firmada por Hegel, fosse ampliada, incluindo o cinema como a sétima arte, precedida pela arquitetura, escultura, pintura, música, dança e poesia. Curiosamente o teatro não aparecia listado no manifesto como uma forma de arte independente, pois combinaria várias outras linguagens artísticas já existentes.

O cinema, então, como o teatro, não poderia ser considerado como arte porque apenas congregava várias outras linguagens, deveria ele possuir algo único que o elevasse a este status. Esta condição de arte não é uma construção fácil de ser compreendida. Podemos tomar inicialmente o elemento da narrativa fílmica, introduzida a partir de 1902 por Georges Meliès, como um fator determinante. Se o cinema nas suas origens se ocupava apenas na exibição de cenas desconexas do cotidiano humano, Meliés, ao contar a fantástica história de homens que fazem um foguete e vão a lua, inova ao propor uma abordagem ficcional.

Se o cinema por meio da narrativa fílmica é capaz de contar histórias, será também capaz de problematizar situações e eventos. É a partir desta perspectiva que o cinema vai criando seus gêneros, terror, suspense, western, drama, comédia, enfim, não servirá apenas para "mostrar cenas", mas será capaz de problematizar algo inerente à nossa realidade.

Porém o início do século XX fora conturbado, principalmente com a força através da qual os estudiosos frankfurtianos dirigiam suas críticas ao neo-capitalismo e a um dos seus mais fortes braços: a indústria cultural, da qual o cinema fazia parte. Walter Benjamin, filósofo e teórico frankfurtiano, acreditava na força revolucionária do cinema, 
porém temia pelas conseqüências do seu desenvolvimento. Em 1935, quando escreveu o ensaio intitulado A obra de arte na era de sua reprodutibilidade técnica ${ }^{2}$ havia um grande impasse sobre as conseqüências do desenvolvimento do cinema como uma forma de arte.

A reprodução em massa dos filmes visando cada vez mais um público menos esclarecido fazia com que o desenvolvimento do cinema se colocasse como uma verdadeira incógnita. Benjamin (2010) revela que as obras de arte têm sua reprodução assegurada há muitos séculos, desde quando os discípulos já imitavam as obras de arte de seus mestres, porém, a utilização de uma técnica na reprodução de obras de arte era algo novo, já implementada pela técnica da xilogravura. "À xilogravura na Idade Média, seguem-se à estampa em chapa de cobre e a água-forte, assim como a litografia, no inicio do século XIX." (BENJAMIN, 2010, p.1). Com a litografia, a reprodução atinge um novo estágio, pois, além de permitir a reprodução em massa, ainda colocava novos produtos a disposição dos consumidores. A litografia por sua vez foi superada pela fotografia, que segundo o filósofo será, juntamente com a reprodução técnica do som, a principal responsável pela criação do cinema:

A reprodução técnica do som iniciou-se no fim do século passado (XIX). Com ela, a reprodução técnica atingiu tal padrão de qualidade que ela não somente podia transformar em seus objetos a totalidade das obras de arte tradicionais, submetendo-as a transformações profundas como conquistar para si um lugar próprio entre os procedimentos artísticos. Para estudar esse padrão, nada é mais instrutivo que examinar como 
suas duas funções - a reprodução da obra de arte e a arte cinematográfica repercutem uma sobre a outra. (BENJAMIN, 2010, p.1)

Para Benjamin, o problema do cinema como arte se coloca no sentido de que a essência do filme é a sua reprodução. A reprodução por sua vez privaria a obra de sua autenticidade, não podendo ser considerada como uma forma de arte. Pinturas como "A Criação de Adão" de Michelangelo, por exemplo, são verdadeiras obras de arte porque são únicas, não podendo existir nenhuma outra igual. Para Benjamin, a obra de arte possuiria uma espécie de "aura" que conferiria o status de arte à obra. Segundo Benjamin (2010) a aura de uma obra de arte

[...] é uma figura singular, composta de elementos espaciais e temporais: a aparição única de uma coisa distante por mais perto que ela esteja. Observar, em repouso, numa tarde de verão, uma cadeia de montanhas no horizonte, ou um galho, que projeta sua sombra sobre nós, significa respirar a aura dessas montanhas, desse galho. (BENJAMIN, 2010, p.3)

Para Benjamin (2010) a reprodutibilidade técnica leva a perda ou a destruição da aura da obra de arte. A reprodução serial, em primeiro lugar, substitui a "unicidade" do objeto de arte, em segundo porque ao permitir que a cópia desta obra de arte chegue ao espectador ela atualiza o objeto reproduzido. Destrói-se assim não apenas a autenticidade da verdadeira obra de arte, mas toda a tradição cultural à qual ela estava submetida neste movimento de substituição, 
destruição e atualização da obra de arte enquanto cópia ou imitação. A imitação ou a cópia não possui história, muito menos um contexto cultural do qual ela deriva, ela é artificial na medida em que é despojada de uma tradição. Segundo o filósofo:

A reprodutibilidade técnica do filme tem seu fundamento imediato na técnica de sua produção. Esta não apenas permite, da forma mais imediata, a difusão em massa da obra cinematográfica, como a torna obrigatória. A difusão se torna obrigatória, porque a produção de um filme é tão cara que um consumidor, que poderia, por exemplo, pagar um quadro, não pode mais pagar um filme. (BENJAMIN, 2010, p.3)

Benjamin defende a ideia de que historicamente a arte sempre foi reprodução, isso não seria um fenômeno tipicamente produzido pela indústria cultural, mas algo que já é apresentado há séculos na história humana. Benjamin cita alguns exemplos, como a xilogravura, a litografia e a fotografia, fenômenos dos quais o cinema havia sido apenas uma consequência tecnológica.

Em sua essência, a obra de arte sempre foi reprodutível. $\mathrm{O}$ que os homens faziam sempre podia ser imitado por outros homens. Essa imitação era praticada por discípulos, em seus exercícios, pelos mestres, para a difusão das obras, e finalmente por terceiros, meramente interessados no lucro. Em contraste, a reprodução técnica da obra de arte representa um processo novo, que se vem desenvolvendo na história 
intermitentemente, através de saltos separados por longos intervalos, mas como intensidade crescente". (BENJAMIN, 2010, p.5)

O filme, porém, não poderia ser comparado com as demais obras como a pintura, por exemplo. Isto porque o custo que demanda a produção de um filme é relativamente mais alto do que a produção de um quadro. O filme seria, portanto, não um traço do individualismo, mas uma característica que ligava a sua produção a uma coletividade.

Nas obras cinematográficas, a reprodutibilidade técnica do produto não é, como no caso da literatura ou da pintura, uma condição externa para sua difusão maciça. A reprodutibilidade técnica do filme tem seu fundamento imediato na técnica de sua produção. Esta não apenas permite, da forma mais imediata, a difusão em massa da obra cinematográfica, como a torna obrigatória. A difusão se torna obrigatória, porque a produção de um filme é tão cara que um consumidor que poderia, por exemplo, pagar um quadro, não pode mais pagar um filme. O filme é uma criação da coletividade. (BENJAMIN, 2010, p.6)

O cinema segundo Benjamin é capaz de penetrar no âmago da realidade. Benjamin identifica no cinema uma proposta revolucionária, pois o cinema não estaria ligado apenas a uma elite, mas poderia ser difundido entre a massa, modificando sua consciência diante dos fatos. A consciência do homem comum é alterada na modernidade, que seria retrógrada diante de um Picasso, mas progressista diante de 
um Chaplin. O cinema teria uma função primordial ao ser o responsável por um equilíbrio entre o homem e o aparato técnico.

Adorno (apud STAM, 2003), ao contrário de Benjamin, não via no cinema apenas uma forma de fetichização da arte, mas de destruição da mesma, pois o cinema seria sobretudo uma forma pura de conduzir o homem aos processos de alienação. Segundo Stam:

Em uma série de respostas epistolares aos ensaios de Benjamin, o teórico crítico da Escola de Frankfurt, Theodor Adorno, acusou-o de um utopismo tecnológico que a um só tempo fetichizava a técnica e ignorava o seu alienante funcionamento social na realidade. Adorno foi bastante cético com respeito às afirmações de Benjamin sobre as possibilidades emancipatórias dos novos meios e formas culturais. A celebração benjaminiana do cinema como um veículo para a consciência revolucionária, para Adorno, ingenuamente idealizava a classe trabalhadora e suas aspirações pretensamente revolucionárias. (STAM, 2003, p. 86)

A posição de Benjamim é antagônica a de Adorno. Adorno destacou os aspectos negativos do cinema e de como o mesmo seria um instrumento alienante. Benjamin, porém, acreditava na característica singular do cinema, apesar de reconhecer que algumas produções poderiam ter um efeito negativo, como as da Disney citadas em seu artigo. Segundo Kothe (1978, p.37), Benjamin destacou as possibilidades abertas pela tecnologia e as conseqüências positivas desta percepção modificada (especialmente a dessacralização), 
enquanto "Adorno, apontou as consequências negativas e as deficiências ali presentes. Para o primeiro, um salto qualitativo para frente; para o segundo, para trás".

Fiquemos por ora com a posição de Benjamin e vejamos os desdobramentos possíveis do cinema como um fator para a educação. Após a morte de Benjamin, delineava-se cada vez mais o fortalecimento do cinema como arte, através de vários movimentos cinematográficos que buscavam uma significação artística para o cinema, sendo que a década de 30 já apresentava um cinema soviético robusto e movimentos de vanguarda na arte cinematográfica, como o realismo poético francês, posteriormente ganhando força com o neorealismo italiano no pós-guerra. A questão é que estes movimentos tiveram como motor em primeiro lugar, os espaços ocupados pela crítica cinematográfica nas principais revistas em circulação na época, em segundo, devido à potencialidade das discussões fomentadas pelos cineclubes, uma vez que os cineclubes colocaram-se como os principais centros de discussão do cinema como uma forma de arte. Aos cineclubes cabe direcionar agora a nossa reflexão, a fim de que possamos encontrar em sua potencialidade uma função educativa e emancipadora.

\section{PARTE 2: CINECLUBISMO E EDUCAÇÃO: UMA PROPOSTA EMANCIPADORA}

O cineclube desde sua origem teve um pressuposto educativo. Se lembrarmos da gênese da crítica de cinema francesa, a mesma só existiu se tomarmos como pressuposto 
as discussões que partiam dos cineclubes, dos quais muitos dos participantes eram críticos de cinema de algumas revistas da época, como é o caso de André Bazin e até mesmo de cineastas como Jean Luc Godad. A questão é que o cineclube enquanto espaço de discussão possibilita múltiplas abordagens, além de permitir a coexistência de diferentes perspectivas a partir da mesma obra. Ao falar sobre a obra e escutar a análise de outros participantes, a discussão se transforma num elemento educativo.

É a partir deste fato que podemos pensar nas ideias do cineclube como um espaço de formação educativa e do cinema como um fator de educação. Literalmente como fator, pois o cinema tende a estar ao alcance de muitas pessoas, uma vez que ao surgir como entretenimento de massa, sua popularização ocorreu de forma absurdamente rápida: Serrano (1932) e Venâncio (1941) já avaliavam e advertiam os educadores da potencialidade da utilização do cinema como fator de educação.

[...] eis porque, se não é em absoluto exato afirmar a possibilidade da educação integral só por meio do cinema, é perfeitamente razoável considerar a prodigiosa invenção como um dos recursos e dos mais eficientes, e até com alguns privilégios intransferíveis, para a grande obra do ensino. (SERRANO, 1932, p. 176-177)

Dizia Bernard Shaw que o livro deve agradar $1 \%$ dos leitores, e o teatro $10 \%$ dos espectadores, o cinema $90 \%$, donde a necessidade de se vulgarizar, de se nivelar com o gosto da maioria. Parece que, por isso mesmo, que deve agradar e pode agradar ao grande público, é que o cinema é, de fato, um grande fator de educação (fator 
no próprio sentido do termo - multiplicador), pois que, como nenhum outro, pode ensinar, pode educar a todos, mesmo aos que não sabem ler. (VENÂNCIO, 1941, p.4243)

Tecnologicamente, na atualidade temos muitas possibilidades de disseminar a prática do cineclubismo, até mesmo porque a execução deste tipo de projeto não exige mais o domínio de uma tecnologia cara, como no caso dos projetores mais antigos e da aquisição dos rolos de filmes fornecidos pelas distribuidoras aqui no Brasil. Essas facilidades começam a surgir no mercado após o surgimento de outras mídias.De acordo com Mascarello (2006, p.348), podemos perceber isso como o surgimento de filmes gravados em fitas magnéticas, mercado criado nos EUA a partir de 1975, como o Betamax e do famoso VHS (Vídeo Home System) na década de 1980. Em nosso país, este mercado das chamadas "fitas cassetes" começou em 1982, criando um novo mercado consumidor e abrindo novos nichos de mercado, como as vídeo-locadoras, além de facilitar a montagem de cineclubes (espaço dedicado ao debate de filmes e a crítica de cinema) de norte a sul do país.

Segundo Campos e Silva (2010), a popularização do filme intensificou-se a partir do ano de 2003, com a produção dos aparelhos de DVD (Digital Vídeo Disk) que foram substituindo gradualmente as fitas cassetes no mercado brasileiro. $\mathrm{O}$ formato compacto, a facilidade do uso e a diversidade de títulos novos e antigos, fez do DVD um produto útil e de baixo custo no mercado. Em 2010 aparece um novo formato, 
o Blu-Ray, que comportando filmes em alta definição (1080p), enterrara definitivamente o problema gerado pelos formatos anteriores.

$\mathrm{Na}$ atualidade, os Vídeos On-demand (VoD) têm ocupado um espaço cada vez maior na transmissão de conteúdos audiovisuais através de sites na internet. $\mathrm{O}$ mais popular deles, NETFLIX, conquistou o mercado mundial ao oferecer séries e filmes em alta definição de imagem por baixíssimo custo, o que provocou a ira das empresas de TV a cabo que há muitos anos impunham sobre seus assinantes altos custos de mensalidade, deixando muitas vezes a desejar na qualidade da prestação dos serviços.

A facilidade tecnológica se coloca como um fator determinante para que possamos disseminar a ideia da educação pelo cinema por intermédio dos cineclubes. Além da possibilidade de formação estética por meio da discussão fílmica, os cineclubes se constituem num importante instrumento de formação e conscientização política e social ao proporem uma reflexão democrática e ampla sobre diferentes processos que permeiam a sociedade. Sobre esta questão, Alves e Macedo (2010) fazem uma afirmação interessante:

Formar sujeitos humanos capazes de escolhas radicais é um ato subversivo na ordem burguesa. Na medida em que a prática cineclubista conseguir elaborar metodologias pedagógicas capazes de ir além da mera exibição do filme e inclusive, da mera discussão entretida da narrativa fílmica, ela se coloca num campo precioso da subversão cultural contra a ordem imbecilizante do capital (ALVES; MACEDO, 2010, p. 12). 
Nesta "ordem imbecilizante do capital" citada pelos autores, podemos perceber claramente a perspectiva comercial do cinema, que atende exclusivamente aos caprichos da indústria cultural. Nesse sentido, os cineclubes fazem o contrabalanceamento da fórmula ao proporem suas análises a partir de filmes que ressaltem a essência do cinema enquanto arte e não apenas como elemento comercial, como popularmente vemos muitas das produções norte americanas.

Porém, para que o cinema possa ser tomado como fator de educação, é essencial que ele esteja dentro de um espaço propício para sua execução: a escola. Há muitos anos que se defende a ideia de que o cinema deve ocupar um lugar cativo no seio escolar. Isto se deve ao fato de que é inegável que o cinema pode contribuir para a formação crítica e pessoal dos estudantes. Pensar a escola como um espaço de formação crítica e cidadã é algo que vai além da própria proposta constante na LDB. Ela evoca uma necessidade primordial que é fornecer aos jovens a capacidade de pensar por si mesmos, de serem indivíduos autônomos e ativos dentro do seu espaço social de interação.

$\mathrm{Na}$ escola, porém, o cineclube deve ser pensado com alguns cuidados, isto porque todo cineclube deve levar em conta o seu público alvo e sua especificidade. Poderia afirmarse que os cineclubes constituem verdadeiros instrumentos de pesquisa ao possibilitarem diferentes reflexões sobre processos diversificados que fazem parte da educação do mundo juvenil.

$\mathrm{Na}$ atualidade presenciamos cada vez mais a intensificação de processos ligados ao consumo, como 
a neofilia, a reificação e a fetichização dos processos sociais. A ideia de uma "felicidade paradoxal", tal qual apontada pelo filósofo contemporâneo Lipovetsky em sua obra Felicidade Paradoxal: Ensaio sobre a sociedade de hiperconsumo (2007), tende a produzir uma massa de pessoas alienadas pelo consumo, incapazes de pensar a sua realidade de forma crítica e coerente, não sendo capazes de serem os atores de uma nova proposta de realidade cultural. A busca pelo esclarecimento e pelo processo de emancipação passa indiscutivelmente por uma educação que priorize o diálogo e a vivência com diferentes pontos de vista. No horizonte destas questões, o cineclube aparece como uma proposta interessante.

Os mecanismos de produção da alienação cultural visam produzir homens e mulheres deformados enquanto sujeitos humanos capazes de intervenção radical. Matase, na raiz, o processo de democratização da vida social e inverte-se o ideal democrático numa mera fórmula manipulatória da opinião pública visando manter os parâmetros da velha e caduca ordem burguesa em sua etapa de crise estrutural. Por isso, coloca-se como tarefa crucial hoje, a disseminação de práticas de formação humana no sentido da efetivação de sujeitos críticosreflexivos capazes de intervenção radical (ALVES; MACEDO, 2010, p. 14-15).

Pensar a educação atual como dissociada da tecnologia é um retrocesso. Por isso a escola não deve atuar como uma instituição que inibe e proíbe o uso da tecnologia, deve antes pensar na utilização pedagógica das novas tecnologias, 
pois como afirmou Hans Jonas em sua obra O Princípio da Responsabilidade (2006), o problema nunca está com a tecnologia, mas sim no uso que fazemos dela. Nesse sentido, cabe pensar sobre o uso das tecnologias como elementos que irão nos auxiliar no processo de ensino aprendizagem no interior da escola, como é o caso aqui apresentado do filme.

O cineclube na escola é um importante mecanismo de reflexão que pode oferecer uma possibilidade de uma nova ressignificação da nossa realidade cultural, social e política por intermédio da exibição dos filmes do cinema mundial. Segundo Alves e Macedo (2010, p.16), "refletir significa 'voltar-se sobre si mesmo', que é o sentido etimológico da palavra latina reflexione. O movimento da reflexão crítica no sentido intelectual e moral é a verdadeira significação da formação humano-genérica". É desta forma que podemos lançar uma justificativa importante na utilização do cineclube como um espaço de discussão e reflexão fílmica.

Porém, a realização de uma sessão cineclubista na escola nos coloca alguns desafios. O primeiro deles diz respeito à compreensão deste processo que emana a partir do filme. O processo de realização de uma sessão cineclubista possuem algumas peculiaridades na qual cabe destacar que tal evento é, na verdade, um ritual que perpassa as três etapas da "santíssima trindade baziniana", a saber, a apresentação, a exibição e o debate. Esta composição possibilita por parte do espectador uma interpretação e significação dos valores, ideias e conceitos apreendidos por intermédio do filme, sendo que tais etapas podem ser definidas como a apropriação, a significação e por último, a reapropriação/ 
ressignificação, descritas no quadro logo abaixo:

\begin{tabular}{|l|l|l|}
\hline \multicolumn{1}{|c|}{ Apropriação: } & \multicolumn{1}{|c|}{ Significação: } & \multicolumn{1}{c|}{ Reapropriação/ressignificação: } \\
(Exibição do Filme: o & (Após o filme, & (Após o encerramento da sessão \\
indivíduo apropria-se & realiza-se o debate e & opera-se o início da elaboração de \\
da imagem a partir & discussão de ideias & uma nova concepção e entendimento \\
do impacto ou da & e conceitos-imagem & a partir da reflexão e das diferentes \\
violência causada pela & iniciais presentes no \\
mesma na mente do & filme, conferindo um \\
espectador) & primeiro significado/ & ideias apresentadas na discussão pós- \\
& filme) \\
& $\begin{array}{l}\text { interpretação a partir } \\
\text { da perspectiva dos } \\
\text { presentes) }\end{array}$ & \\
&
\end{tabular}

PROCESSO DE APRENDIZAGEM FILOSÓFICA NO CINECLUBE FONTE: O autor (2016)

Quando analisamos a tabela, percebemos que o processo educativo se inicia na exibição fílmica, onde num primeiro momento o aluno terá contato com a narrativa fílmica. A imagemmovimento agirá sobre a mente do educando no sentido de produzir uma reflexão inicial a partir da problemática apontada pelo filme. $\mathrm{O}$ aluno-espectador se apropria então da perspectiva fílmica contida na narrativa e passa a pensá-la partir de suas próprias ideias e reflexões.

Num segundo momento, após a exibição do filme, temos a discussão ou debate livre de ideias. Neste momento serão apresentadas diferentes perspectivas sobre o mesmo elemento, o que provocará um choque de conceitos. Os alunos tentarão defender, justificar ou verão suas teses iniciais serem colocadas em xeque ao perceberem as possíveis contradições a partir da fala dos demais cineclubistas. Esse processo oferece uma nova possibilidade de significação, para além daquilo que foi colocado pelo próprio indivíduo durante a exibição do filme. 
Ao final, a partir dos diferentes pontos de vista, acontece uma reconstrução do observado, do sentido e do pensado. Os alunos, tendo posse do resultado da discussão, ou permanecem firmes em suas convicções, ou são abalados e forçados a reconstruírem seus argumentos e perspectivas. Esse processo opera uma ressignificação dos conceitos discutidos a partir do filme provocando uma reapropriação por parte do espectador. Cabe ressaltar que este processo não se finda com o encerramento da sessão cineclubista, pois o educando pode levar esta reflexão ainda por vários dias a fim de pensá-la de uma forma mais consistente.

Durante a exibição do filme o encadeamento das imagensmovimento transmitem ideias e conceitos que passam a ser pensados com mais profundidade pelo espectador. Essa experiência que afeta tanto o sentir como o pensar tende a afastar o sujeito da realidade onde vive, permitindo pensá-la e transfigurá-la. Toda exibição fílmica promove este afastamento e, portanto, caracteriza-se como um convite ao pensamento e a reflexão, em outras palavras, ao verdadeiro exercício do "filosofar". O pensamento é ação (interna), mas também é algo que paralisa a ação (externa), a vida humana congrega duas esferas, a do mundo prático e a do pensamento, por isso pensar significa afastar-se do mundo prático, e também por isso o filosofar exige tal afastamento conquistado durante a exibição do filme.

O cineclube oferece aos jovens uma nova possibilidade de pensar os problemas inerentes à realidade e à própria condição humana. A partir das sessões, os alunos irão perceber uma nova possibilidade de se confrontarem com as grandes questões que movem o pensamento humano por meio da linguagem cinematográfica. Desta forma, os alunos tendem a ir de encontro a um processo de esclarecimento, de emancipação tal qual descrito 
por Habermas (2002, p. 90), em que a emancipação é tomada "num sentido de libertação de nossas próprias limitações, trata-se de autoexperiência, de esclarecimento, no agir em um sentido de entendimento mútuo" na construção de um diálogo crítico, democrático e sem fronteiras, algo que vai em direção ao que muitos idealizam nos dias atuais como objetivo final dos processos educativos.

\section{CONCLUSÃO}

No presente texto observamos que o filme/cinema tem um espaço privilegiado, afastando-se de seu rótulo da indústria cultural quando pensamos o seu uso educativo por intermédio da prática cineclubista. $\mathrm{O}$ cineclubismo na escola ainda tem uma função importante a cumprir no sentido de propiciar aos jovens uma nova forma de pensar a realidade e seus problemas, promovendo a possibilidade de emancipação e esclarecimento.

Por intermédio dos cineclubes, o ideal educativo torna-se mais palpável, mais próximo de ser alcançado e realizado. A partir da exibição do filme em uma sessão cineclubista, muitas das fronteiras que separam os saberes dissolvem-se durante o debate, na tentativa de buscarmos argumentos para refletir sobre um certo problema evidenciado pela narrativa fílmica na contraposição de diferentes argumentos e perspectivas.

Cabe ressaltar que a prática cineclubista voltada para o ensino da filosofia é de fundamental importância ao propiciar a seus membros a formação de uma consciência crítica por meio da discussão e do debate, promovendo uma educação 
estética, política, social e cultural. Em meio a uma época onde as tecnologias permeiam o mundo do jovem, o cinema, a partir do cineclubismo na escola, aparece dentro de um horizonte favorável, uma vez que vemos a aplicação adequada e correta da tecnologia num sentido tanto didático quanto pedagógico.

\section{NOTAS}

${ }^{1}$ Mestre em Educação (UFPR-2014). Pesquisador Núcleo de Estudos e Pesquisas sobre Ensino da Filosofia (NESEF-UFPR) e coordenador do Grupo de Estudos e Pesquisas sobre Cinema e Filosofia (GECEF). Professor dos cursos de graduação e pós-graduação do Claretiano-Centro Universitário e do Centro Estadual de Educação Profissional de Curitiba (CEEP). E-mail: alessandroreina@claretiano.edu.br.

${ }^{2}$ Este texto é inédito no Brasil. Parte das citações que serão realizadas desta obra de Walter Benjamin remetem-se a uma tradução em documento digital feita por João Maria Mendes a partir da primeira versão do documento original em francês de A Obra de Arte na Era da sua Reprodutibilidade Técnica (19351936), por Walter Benjamin e Pierre Klossowski. 


\section{REFERÊNCIAS}

BAZIN, A. O cinema: ensaios. São Paulo: Brasiliense, 1991.

BENJAMIN, W. A obra de arte na era de sua reprodutibilidade técnica. Primeira Edição. Tradução João Maria Mendes. Biblioteca Escola Superior de Teatro e Cinema. Lisboa, 2010.

CABRERA, J. O cinema pensa: uma introdução à filosofia através dos filmes. Rio de Janeiro: Rocco, 2006.

CAMPOS, M. F.H; SILVA, S. C. A melhoria da qualidade de educação na escola pública: desafios ao uso das TIC. In: Estudos IAT, Salvador, v.1, n.3, dez. 2010. p. 138-154.

DANTAS, M. L.; MOREIRA, W. O Pensar Filosófico Segundo Martin Heidegger. Janus, Lorena, v. 4, n. 6, jul./dez., 2007.

DELEUZE, G. Cinema II: a imagem-tempo. São Paulo: Brasiliense, 2007.

HABERMAS, J. O discurso filosófico da modernidade. São Paulo: Martins Fontes, 2002.

JONAS, H. O Princípio Responsabilidade: Ensaio de uma Ética para a civilização tecnológica. Rio de Janeiro: Contraponto / PUC-RIO, 2006.

LIPOVETSKI, G. A felicidade paradoxal: ensaio sobre a sociedade de hiperconsumo. São Paulo: Companhia das Letras, 2007.

MASCARELLO, F. et al. História do cinema mundial. Campinas: Papirus, 2006. 
NAPOLITANO, M. Como usar o cinema na sala de aula. 2. ed. São Paulo: Contexto, 2003.

REINA, A. Cinema e Filosofia: como ensinar e aprender filosofia com os filmes. Curitiba: Juruá, 2016.

SERRANO, J. A escola nova: uma palavra serena em um debate apaixonado. Rio de Janeiro: Schimdt, 1932.

STAM, R. Introdução à Teoria do Cinema. Campinas, Papirus, 2003.

VENÂNCIO, F. F. A educação e seu aparelhamento moderno. São Paulo: Nacional, 1941. 